\title{
REVIEW
}

\section{Cancer in veterinarians}

\author{
Lin Fritschi
}

\begin{abstract}
Objectives-Veterinarians come into contact with several potentially carcinogenic exposures in the course of their occupation. These exposures include radiation, anaesthetic gases, pesticides (particularly insecticides), and zoonotic organisms. This review aims to summarise what is known about the carcinogenic risks in this profession.

Methods-The levels of exposure to potential carcinogens in the veterinary profession are examined and evidence is reviewed for carcinogenesis of these substances in humans at doses similar to those experienced by veterinarians. The few published studies of cancer in veterinarians are also summarised.

Results-Veterinarians have considerable potential for exposure to several known and potential carcinogens. Risks may be posed by work in clinics with poorly maintained $x$ ray equipment, by use of insecticides, and from contact with carcinogenic zoonotic organisms. The few studies available suggest that veterinarians have increased mortality from lymphohaematopoietic cancers, melanoma, and possibly colon cancer.

Conclusions-The exposures examined in this review are not unique to the veterinary profession, and, as a consequence, information gathered on the carcinogenic risks of these exposures has implications for many other occupations such as veterinary nurses, animal handlers, and some farmers, as well as dentists, radiographers, and anaesthetists.

(Occup Environ Med 2000;57:289-297)
\end{abstract}

Department of

Epidemiology and

Preventive Medicine,

Monash University,

Alfred Hospital,

Prahran 3181,

Australia

L Fritschi

Correspondence to:

Dr Lin Fritschi, Department

of Epidemiology and

Preventive Medicine,

Monash University, Alfred

Hospital, Prahran 3181,

Australia email

lin.fritschi@med.monash.edu.au

Accepted 20 December 1999
Keywords: cancer; veterinarians; occupation

Veterinarians come into contact with several potentially carcinogenic exposures in the course of their occupation including radiation, anaesthetic gases, pesticides (particularly insecticides), and zoonotic organisms. However, very little is known about the carcinogenic risks in this occupation.

In this review, the levels of exposure to potential carcinogens in the veterinary profession are examined and evidence is reviewed for carcinogenesis of these substances. Although evidence on the carcinogenicity for some of these exposures in veterinary practitioners is scant, there are some publications on the carcinogenic effects of similar exposures in other professions. The few published studies of cancer in veterinarians are also summarised.

\section{Exposures in veterinary medicine} $x$ RAYS

Exposure levels

It is thought that most practicing veterinarians use radiographic equipment. In a postal survey of all women graduating from United States colleges of veterinary medicine in the 1970 s, $64 \%$ of subjects stated that they had been exposed to radiation during pregnancy. ${ }^{1}$ This survey achieved an impressive response of $90 \%$ with a sample size of 2427 .

In another postal survey of all women who had graduated from the University of California with a veterinary medicine degree, $82 \%$ had potential exposure to ionising radiation. ${ }^{2}$ Again the response was high (86\%) and the sample size quite large $(n=457)$. This survey may be more representative of usual exposures than the other, as the exposures were not confined to those experienced during pregnancy. Exposure to $x$ rays was most common in small animal practice $(90 \%)$ as opposed to large animal practice $(77 \%)$ and other practice $(52 \%)$. Of those who reported taking $x$ ray films, $43 \%$ took more than five a week, and $22 \%$ took more than 10 a week.

The annual occupational permissible dose according to the International Commission on Radiological Protection is $20 \mathrm{mSv}$. A study was conducted of women veterinarians living in three states who had graduated from a United States veterinary school during the 1970 s. $^{3}$ One hundred and eighteen subjects $(91 \%$ of those eligible) agreed to wear radiation dosimeters for 3 months and results were available for $86 \%$ of those. Exposures $>1.5 \mathrm{mSv} /$ month were recorded for $20(9.2 \%)$ of the 271 person-months monitored. These doses are well below the maximal permissible dose for occupational exposure; however, it is possible that the veterinarians changed their behaviour as they knew they were being monitored.

In the United Kingdom, the National Radiation Protection Board (NRPB) surveyed 50 veterinary practices in $1993 .{ }^{4}$ In each practice, the "person normally standing closest to the $x$ ray machine" wore body and extremity dosimeters for 1 month. Doses were only recorded in three of the 50 practices and these were all $<0.3$ $\mathrm{mSv}$. 
There are several factors specific to veterinary practice which may affect the radiation dose, including the need to restrain the animal during procedures, poorly maintained equipment, and lack of training in radiation safety. In the Californian survey, ${ }^{2} 76 \%$ of respondents reported restraining animals at least once a month during $x$ ray procedures. The NRPB report stated that "manual restraint of animals would appear to be still practised perhaps more frequently than is desirable or necessary" with many practices restraining more than $50 \%$ of animals undergoing radiography. ${ }^{4}$

Studies before 1980 found high prevalences of poorly shielded radiographic equipment and protection practices in veterinary surgeries. ${ }^{5-7}$ However, even in 1987 a survey of 29 randomly selected veterinary practices with radiographic equipment in Ohio, USA (with $83 \%$ response) found that not all practices complied with safety guidelines. ${ }^{8}$ This study used only practices which had their radiography machines registered with the Department of Health, and we are not told whether this would include all practices with radiology facilities. Collimators, which narrow the $x$ ray beam, were not present in $14 \%$ of practices. Lead aprons and gloves were available in most practices, but were not often tested for leaks. Film badges were worn in about half the practices, with some practices sharing the badges between several people. Lead lining was present in only two practices, with a lead lined shield available in a further five practices (total $=24 \%$ ). The dosimetry study of United States female veterinarians already described ${ }^{3}$ found similar results with most subjects wearing lead aprons and gloves, but only $38 \%$ of practices having a lead shield. The NRPB study found that most $x$ ray machines were old (modal age 20 years) and many were poorly maintained; however, the $x$ ray rooms seemed to provide adequate screening in most cases. ${ }^{4}$ The NRPB developed a "vet pack" to help veterinarians meet standards for $x$ ray equipment and procedures; however, this has recently been discontinued due to lack of interest from the veterinary profession.

There are several papers describing the exposure of radiologists and surgeons to radiation. Monthly doses of physicians in emergency departments, who might be expected to only have occasional exposure to $x$ rays, have been measured at $0.0012 \mathrm{mSv} .^{9}$ Radiologists working with diagnostic radiology have been reported as receiving $0.1-0.5 \mathrm{mSv}$ monthly and those working in therapeutic radiology may have slightly higher doses..$^{11}$ Orthopaedic surgeons who use fluoroscopy may have quite high exposures to the hands although in $80 \%$ of procedures the dose is $<0.1 \mathrm{mSv}^{12}$ Thus it seems that veterinarians currently have lower exposures than radiologists and surgeons.

Evidence for carcinogenicity at exposure levels similar to veterinarians

The carcinogenic effects of ionising radiation have been recognised for many years, particularly for skin cancer, thyroid cancer, and leukaemia. ${ }^{13}$
Cohorts of radiologists have been examined in the United States ${ }^{14}$ and the United Kingdom, ${ }^{15}$ with complete population enumeration and nearly complete follow up for mortality but no data on cancer incidence. Both studies found that radiologists who started practice before 1920 had increased death rates from skin cancer and leukaemia compared with other physicians ${ }^{14}$ or to the English population. ${ }^{15}$ In more recent cohorts there have been no significant differences between death rates for any cancer in radiologists compared with other doctors. ${ }^{16}$ Physicians may be expected to have their cancers diagnosed earlier or perhaps treated better, and this bias could be assessed by examining incidence of cancer.

A case-control study found that women dentists and dental nurses had 13 times the risk of thyroid cancer compared with those not in these two occupations. ${ }^{17}$ However, this result was based on only seven exposed cases and one exposed control and 95\% confidence intervals ( $95 \%$ CI) were extremely wide (95\% CI 2.1 to 389). Record linkage studies have suggested that dental personnel have an increased risk of melanoma ${ }^{18-20}$ as well as raised risk of colorectal cancer, ${ }^{18}$ although both these cancers are associated with higher socioeconomic status and not necessarily with $x$ rays or other occupational substances.

\section{ANAESTHETICS}

Exposure levels

Almost all practicing veterinarians perform surgery and much of this involves general anaesthesia. The anaesthetic equipment used in veterinary surgery is similar to that used in human hospitals. Animals are usually initially anaesthesised with an injectable anaesthetic, then maintained on inhalational anaesthetics. ${ }^{21}$ Both rebreathing and non-rebreathing systems are used and the main substances used are halogenated anaesthetics and nitrous oxide.

In the studies of American women veterinarians already described, exposure to anaesthetic gas was reported by between $63 \%$ and $83 \%$ of female veterinarians. ${ }^{12}$ A further study of private veterinary practices in Colorado, USA, found that $81 \%$ of practices used inhalation anaesthetics, although use varied with type of practice: $90 \%$ of small animal practices and $59 \%$ of large animal practices. ${ }^{21}$

The National Institute for Occupational Safety and Health (NIOSH) recommends that exposures to halogenated anaesthetics be maintained below $2.0 \mathrm{ppm}$ with a time weighted average (TWA) of $50 \mathrm{ppm}^{21}{ }^{22}$ Halothane concentrations in veterinary surgeries seem to exceed the maximal limit in 30\%$50 \%$ of measurements. ${ }^{22-24}$ Personal monitoring ranges from $0.7 \mathrm{ppm}$ to about $20 \mathrm{ppm}^{22} 24-27$ although measurements of up to $105 \mathrm{ppm}$ have been recorded. ${ }^{27}$ Calculated 8 hour TWAs tend to be lower at around $1.2 \mathrm{ppm} .{ }^{23}$ It has also been shown that concentrations of halothane in recovery rooms may be above the NIOSH recommendations for up to 2 hours as the patient is recovering from the operation. ${ }^{28}$ 
For nitrous oxide, NIOSH recommends exposures be maintained at $<25 \mathrm{ppm}^{21} 22$ with a TWA of $50 \mathrm{ppm}^{26}$ This concentration is exceeded in most $(75 \%)$ surgeries. ${ }^{22}$ Personal exposure has been measured at between $6 \mathrm{ppm}$ and $270 \mathrm{ppm}^{.22}$ The geometric mean exposure to nitrous oxide of 23 United Kingdom veterinarians was $75 \mathrm{ppm}$ and when calculated as an 8 hour TWA this was 27 ppm. $^{23}$

Use of scavenging systems reduces anaesthetic exposures considerably. ${ }^{2123-25} 29$ However, waste anaesthetic gas scavenging is not used in many veterinary practices. In the United States, use was reported in only about $10 \%$ of practices in surveys done during the $1980 \mathrm{~s}^{24}{ }^{25}$ In more recent studies in the United Kingdom $50 \%$ of surveyed practices had scavengers ${ }^{23}$ whereas in Canada all 10 clinics surveyed had scavengers. ${ }^{26}$ However, most equipment included passive rather than active systems. $^{2326}$

Although measured values of anaesthetics are higher than recommended for human hospitals, veterinarians spend less time than human anaesthetists with anaesthetics. Most small animal veterinarians spend 5-20 hours a week performing surgery and in the recovery room. ${ }^{2126}$ On days when veterinarians are in the operating room, the average daily time spent using anaesthetics is 1.8 hours. ${ }^{24}$ In comparison, the mean time spent weekly in theatres by human anaesthetists as shown by a postal survey was 33.2 hours and by surgeons it was 12.8 hours. $^{30}$

Evidence for carcinogenicity at exposure levels similar to veterinarians

The main concern with anaesthetics is for their reproductive rather than carcinogenic effects. The evidence for carcinogenicity of volatile anaesthetics was reviewed by the International Agency for Research in Cancer in $1987 .{ }^{31}$ There were some reports of increases in lymphohaematopoietic and pancreatic cancers but these were not consistent over the few studies reported. It was concluded that there was not enough information available to classify volatile anaesthetics as to their carcinogenicity. Two more recent cohort studies which included registered British anaesthetists found no significant increases in lymphohaematopoietic or pancreatic cancers. ${ }^{1632}$ An increased risk of dying from melanoma (relative risk (RR) $3.33,95 \%$ CI 1.22 to 7.25 ) was found in one study. ${ }^{16}$ Several postal questionnaire studies have not found increased reported cancer among anaesthetists in North America and the United Kingdom, although site specific rates were not reported, and responses were around $75 \% .^{30}{ }^{33}$ A survey of 44000 dentists and chairside assistants with a $70 \%$ response, found very small non-significant increases in risk of self reported incident cancer (any site) for those with heavy exposure to anaesthetics compared with those with no exposure. ${ }^{34}$

\section{INSECTICIDES}

Exposure concentrations

Practising veterinarians are often exposed to insecticides, primarily through cutaneous ex- posure to flea dips and other pet products. ${ }^{2}$ In the two surveys of women veterinarians already described, exposure to pesticides in the past year was reported by $52 \%$ of women veterinarians $s^{2}$ and exposure during pregnancy was reported by $84 \% .{ }^{1}$ Of those exposed in the previous year, $49 \%$ stated that they had been exposed to pyrethrins, $36 \%$ mentioned carbamates, and $2 \%$ mentioned captan. ${ }^{2}$

There are few publications on quantitative exposures to insecticides in the veterinary profession. In large animal practice, veterinarians may treat cattle with "pour on" organophosphate insecticides. A survey of 18 volunteer veterinarians known to be performing this treatment found that some had experienced mild symptoms of poisoning, but there was no consistent and progressive depression of blood cholinesterase activities. ${ }^{35}$ The finding of acute effects of organophosphate insecticides does not necessarily mean that doses are sufficient for any chronic effects to occur. It was also acknowledged in this paper that the types and quantities of insecticides used were not necessarily typical of bovine veterinary practice.

Animal groomers and pet handlers are also exposed to flea control products which are used by veterinarians. A telephone survey of nearly 700 pet handlers, $40 \%$ of whom were veterinary clinic workers, was conducted in California with a $77 \%$ response. ${ }^{36}$ Handlers who applied flea control products were significantly more likely to report symptoms such as skin rash, tearing, unusual tiredness, burning of the eyes, and flushing of skin than those who did not apply products. A postal survey of licenced pet applicators and applicators working in veterinary surgeries in New Jersey found that $36 \%$ of respondents had experienced at least one of the 17 symptoms associated with insecticide application. ${ }^{37}$ Only $27 \%$ of the sample participated in this survey, which may mean that these findings overestimate the proportion of applicators who develop symptoms. Both these surveys used self report of symptoms and did not measure acute or chronic exposures objectively.

Evidence for carcinogenicity at exposure levels similar to veterinarians

There is considerable interest in the possible carcinogenic effects of pesticides. Part of the difficulty of studying the effects of pesticides is that there are many different groups including insecticides, herbicides, and fungicides. Each group includes many different chemicals, each of which may have a different structure, a different mechanism of action, and different carcinogenicity. Although there are many studies which examine herbicides and their contaminants, for which the links with cancer are perhaps strongest, the interest for veterinarians is rather with organophosphate insecticides and carbamates, both of which are used on animals to control parasites.

Use of insecticides for flea and tick control in domestic pets is one method of exposure for veterinarians. Domestic use of insecticides has been investigated as a risk factor for childhood brain cancer in two case-control studies. Risk 
was reported to be increased with use of pesticides on pets when the child was also exposed to pets ${ }^{38}$ and with use of flea or tick products antenatally. ${ }^{39}$ The possibility of recall bias in these retrospective studies must be considered to be quite high.

Use of flea and tick dips was found to be a risk factor for bladder cancer in dogs, especially overweight female ${ }^{40}$ but the relevance of this to human carcinogenesis is unknown.

Although farmers have been found to have increased risks of lymphohaematopoietic cancers in meta-analyses and reviews, ${ }^{41}{ }^{42}$ many of these studies considered farmers as one group. For pesticides, the most relevant comparison group for veterinarians is insecticide use in livestock farming and here I will review only studies which examined this particular exposure.

Three case-control studies of non-Hodgkin's lymphoma in rural regions of the United States found no significant increases for any insecticides used on livestock. ${ }^{43-45}$ Only one of the studies ${ }^{43}$ found an increase in risk with use of organophosphates, which was small but significant. Three United States case-control studies were pooled to examine the risk of nonHodgkin's lymphoma with use of lindane (an organochlorine used in dog shampoos and livestock sprays ${ }^{46}$ This study found a slight significant increase in risk of non-Hodgkin's lymphoma with ever use of lindane, which was mostly confined to those who used lindane $>20$ years previously. Self reports of the use of insecticide in farmers are considered to be reasonably accurate because they purchase and use the products themselves. Studies at the ecological level, which used county figures for use of insecticides as the exposure variable, have sometimes ${ }^{47} 48$ but not always ${ }^{49}$ found increased rates of leukaemia and multiple myeloma.

\section{INFECTIOUS AGENTS}

Exposure levels

It has long been known that veterinarians are at increased risk of infections transmitted from animals to humans (zoonoses). The published serological surveys of veterinarians are summarised in table 1 . Most of these studies have examined the classic zoonotic diseases such as brucellosis, Q fever, and toxoplasmosis. These diseases have not been associated with cancer; however, the discrepancies between prevalences in veterinarians and the general population show that veterinarians are at high risk of zoonoses. It follows then that if certain zoonoses were associated with cancer, veterinarians would be one of the groups at high risk of cancer.

One survey of veterinarians for a known animal carcinogenic virus was conducted in $1973 .^{50}$ Six hundred and twenty six veterinarians had blood taken for testing for antibodies to feline leukaemia virus (FeLV) Only one veterinarian showed a definite positive result which suggests that human transmission of this virus is rare. However, it is possible that the techniques used at that time for testing for the presence of infection were not sensitive enough. ${ }^{51}$

\section{Evidence for carcinogenicity at exposure levels} similar to those of veterinarians

There are several well described viruses which cause cancer in various animals including bovine papilloma virus and FeLV. ${ }^{52}$ There are also several viruses known to cause cancer in humans including herpes papilloma virus which causes cervical cancer and Epstein-Barr virus which causes Burkitt's lymphoma and nasopharyngeal cancer. ${ }^{52}$ Also, it is known that some viruses, including cowpox, foot and mouth disease, and a range of arboviruses, are able to pass from animals to humans.

These facts have resulted in some speculation about the possibility that carcinogenic viruses in animals could be transmitted to humans where they could cause cancer. ${ }^{414251}$ Speculation has concentrated on lymphohaematopoietic cancers as there is already evidence that some of these types of tumours can be caused by viruses.

One line of investigation is to find whether the risks of lymphohaematopoietic cancer are higher in occupations in which there is contact with animals or animal products. Several cohort studies of butchers and meatcutters have, on the whole, shown no increase in lymphohaematopoietic cancers compared with national rates or with non-meatworkers in the same union ${ }^{53-55}$ although a subanalysis of poultry workers in one of these cohorts had an RR of $2.9(95 \% \text { CI } 1.0 \text { to } 81)^{56}$ The SMR for these poultry workers was not increased. A nested case-control study in the same cohort was

Table 1 Serological surveys of zoonoses in veterinarians

\begin{tabular}{|c|c|c|c|c|c|}
\hline Organism & First author, year ef & Vets $(n)$ & Positive prevalence (\%) & $\begin{array}{l}\text { Criterion for } \\
\text { positive }\end{array}$ & Notes \\
\hline Bartonella & Noah, $1997^{95}$ & 198 & 8.1 & $>1 / 64$ & $2 \%$ Prevalence in US blood donors \\
\hline \multirow[t]{4}{*}{ Brucella } & Nowotny, $1997^{96}$ & 137 & 0 & $?$ & \\
\hline & Robinson, $1976^{97}$ & 86 & $91(3)$ & any $(1 / 160)$ & \\
\hline & Schnurrenberger, $1964^{98}$ & 844 & 6.3 & $1 / 20$ & $17.4 \%$ Prevalence among general practitioners \\
\hline & Morse, $1955^{99}$ & 65 & $38(1.5)$ & any $(1 / 160)$ & \\
\hline \multirow[t]{4}{*}{ Coxiella } & Thibon, $1996^{100}$ & 12 & $67(3)$ & $1 / 16(1 / 320)$ & Healthy controls $<5 \%$ \\
\hline & Htwe, $1993^{101}$ & 275 & 23 & $1 / 16$ & Healthy controls <2\% \\
\hline & Marrie, $1985^{102}$ & 65 & $17-49(3)$ & $1 / 8(1 / 256)$ & \\
\hline & Schnurrenberger, $1964^{98}$ & 844 & 7.6 & $1 / 4$ & $20.7 \%$ Prevalence among large animal practitioners \\
\hline \multirow[t]{5}{*}{ Leptospira } & Nowotny, $1997^{96}$ & 137 & 2.9 & $?$ & \\
\hline & Schnurrrenberger, $1978^{103}$ & 381 & 2 & $1 / 100$ & \\
\hline & Robinson, $1976^{97}$ & 86 & 1 & $1 / 400$ & \\
\hline & Schnurrenberger, $1964^{98}$ & 844 & 0.8 & $1 / 16$ & \\
\hline & Morse, $1955^{99}$ & 104 & 10 & $1 / 10$ & \\
\hline \multirow[t]{2}{*}{ Toxoplasma } & Nowotny, $1997^{96}$ & 137 & 54.7 & $?$ & $10.9 \%$ Prevalence among pregnant Norwegian women \\
\hline & Robinson, $1976^{97}$ & 86 & 3.4 & $1 / 512$ & \\
\hline
\end{tabular}


limited by small numbers and found nonsignificant increases in risks for subjects who worked with raw meat or killed animals. ${ }^{57}$ In case-control studies, meat processors have been found to have significantly increased risks of Hodgkin's disease ${ }^{58}$ and non-Hodgkin's lymphoma ${ }^{59}$ in some but not all studies. ${ }^{44}$ In two North American registry based studies, the occupation of meat cutting was not associated with increased risk of leukaemia. ${ }^{6061}$ All of these studies were limited either by few cases or poor exposure classification.

Lung cancer in meat workers has also been examined with some cohort studies suggesting that pork butchers and packers have increased risks. ${ }^{54} 55$ In a case-control study nested in one of these cohorts it was found that ever working in the meat industry was associated with a 3.6-fold increase in risk of lung cancer (95\% CI 0.7 to 17.9 ) after adjusting for age, sex, race, and smoking. ${ }^{63}$ The risk was higher in those who had worked in the industry $>10$ years before diagnosis.

As discussed previously, the occupation of farming has also been associated with increased risks of lymphohaematopoietic cancers in some but not all studies. For zoonoses there are several studies that have attempted to examine livestock farmers for risk of lymphohaematopoietic cancers (table 2). The results from these studies are not entirely consistent although there is a suggestion that leukaemia may be associated with poultry and cattle farming. Livestock farmers may also have exposure to other possible carcinogens including different types of pesticides (as already discussed) and diesel exhaust.

Another line of approach is to determine whether cancer risk is increased by living in close contact with animals. The risk of lung cancer associated with keeping birds has been extensively investigated ${ }^{64-68}$ but there does not seem to be evidence for a link. ${ }^{69}$

Feline leukaemia virus (FeLV) is a virus which, as its name suggests, causes leukaemia and lymphoma in cats. Simply living with a cat does not seem to increase the risk of leukaemia or lymphoma ${ }^{70} 71$ or lung cancer. ${ }^{64}$ Also, there does not seem to be an increased risk of any type of cancer associated with living with a cat known to have lymphoma. ${ }^{72}$ One early study suggested that exposure to sick cats might be associated with adult leukaemia but the type of sickness was not defined. ${ }^{73}$

Similarly, bovine leukaemia virus causes leukaemia in cattle, but antibodies to it have not been detected in humans in close contact with infected cattle. ${ }^{74}$ Some ecological studies suggest higher rates of leukaemia in areas with many cattle, or where outbreaks of bovine leukaemia virus had been reported but this has not been confirmed in case-control studies. ${ }^{75} 76$

These studies of the risks of exposure to zoonoses are marred by poor exposure assessment. Not all those who live in a household with pets will be exposed to zoonoses, and neither is having no animals in the house a guarantee of non-exposure. ${ }^{77}$ Also, the answers to questions about exposure to sick animals are prone to recall bias and non-specificity of the sickness. ${ }^{77}$

Another line of inquiry has tried to determine whether viruses known to be carcinogenic in animals are transmitted to humans. Avian leukosis and sarcoma viruses (ALSV), reticuloendotheliosis viruses (REV), and Marek's disease virus (MDV) are known to cause cancers of the lymphatic and haemopoietic system in chickens and turkeys. During the 1960 s and 1970 s there was considerable interest in determining whether antibodies to these three viruses could be detected in exposed subjects. Most of these studies were negative although there were technical difficulties with the measurement of antibodies at that time. ${ }^{78}$ Since then, the availability of more sensitive tests for virus detection has resulted in further studies which have concluded that antibodies to all three viruses are more common among poultry workers than among non-exposed controls. ${ }^{79-81}$ Studies have not been able to detect FeLV in human serum samples or in cells from human cancers. $^{82} 83$

\section{Studies of cancer in veterinarians}

A Medline search was made for published studies of cancer in veterinarians since 1966 with all variations on the keywords

Table 2 Summary of case-control studies examining livestock farming and lymphohaematopoietic cancers

\begin{tabular}{|c|c|c|c|c|c|}
\hline First author, yearef & Population & Cancer & Exposure assessment & Exposure & OR $(95 \% C I)$ \\
\hline Milham, $1971^{104}$ & Deaths in two US states & Leukaemia & $\begin{array}{l}\text { Occupation on death } \\
\text { certificate }\end{array}$ & $\begin{array}{l}\text { Poultry farmer } \\
\text { Dairy farmer } \\
\text { Cattle farmer }\end{array}$ & $\begin{array}{l}\mathrm{p}<0.05 \\
\mathrm{p}>0.05 \\
\mathrm{p}>0.05\end{array}$ \\
\hline Blair, $1979^{47}$ & $\begin{array}{l}\text { Deaths in one US state, farmers only } \\
\quad \text { (year of birth 1901-43) }\end{array}$ & Leukaemia & $\begin{array}{l}\text { Per capita agricultural } \\
\text { characteristics }\end{array}$ & $\begin{array}{l}\text { Poultry } \\
\text { Cattle } \\
\text { Pigs }\end{array}$ & $\begin{array}{l}1.6(1.0 \text { to } 2.6) \\
1.7(1.1 \text { to } 2.7) \\
2.0(1.3 \text { to } 3.3)\end{array}$ \\
\hline Cantor, $1984^{48}$ & $\begin{array}{l}\text { Deaths in one US state (excluding } \\
\text { deaths in capital city) all farmers } \\
\text { only }\end{array}$ & Multiple myeloma & $\begin{array}{l}\text { Per capita agricultural } \\
\text { characteristics }\end{array}$ & $\begin{array}{l}\text { Poultry } \\
\text { Cattle } \\
\text { Pigs } \\
\text { Dairy }\end{array}$ & $\begin{array}{l}1.6(1.0 \text { to } 2.7) \\
1.2(0.8 \text { to } 2.0) \\
1.3(0.8 \text { to } 2.0) \\
1.3(0.8 \text { to } 2.1)\end{array}$ \\
\hline Pearce, $1986^{105}$ & $\begin{array}{l}\text { Incident registered cancers in } \\
\text { New Zealand, cancer controls }\end{array}$ & Leukaemia & $\begin{array}{l}\text { Occupation on cancer } \\
\text { registration }\end{array}$ & $\begin{array}{l}\text { Livestock farm } \\
\text { Dairy farm } \\
\text { Poultry farm }\end{array}$ & $\begin{array}{l}3.0(1.2 \text { to } 7.3) \\
1.2(0.4 \text { to } 3.7) \\
0 \text { Cases }\end{array}$ \\
\hline Pearce, $1986^{106}$ & $\begin{array}{l}\text { Incident registered cancers in } \\
\text { New Zealand, cancer controls }\end{array}$ & Multiple myeloma & $\begin{array}{l}\text { Telephone interview, self } \\
\text { reported occupation }\end{array}$ & $\begin{array}{l}\text { Sheep farm } \\
\text { Dairy farm } \\
\text { Mixed farm } \\
\text { Poultry farm }\end{array}$ & $\begin{array}{l}1.9(1.0 \text { to } 3.6) \\
1.4(0.8 \text { to } 2.5) \\
1.3(0.6 \text { to } 2.6) \\
0.9(0.1 \text { to } 8.4)\end{array}$ \\
\hline Clavel, $1995^{107}$ & $\begin{array}{l}\text { Incident cancers in nine French } \\
\text { hospitals }\end{array}$ & Hairy cell leukaemia & Self reported occupation & $\begin{array}{l}\text { Cattle breeding } \\
\text { Sheep breeding } \\
\text { Pig breeding }\end{array}$ & $\begin{array}{l}1.9(1.1 \text { to } 3.1 \\
1.8(0.9 \text { to } 3.6) \\
1.4(0.6 \text { to } 2.8)\end{array}$ \\
\hline
\end{tabular}


veterinarians and cancer. Relevant articles cited in the retrieved articles were also obtained. One case-control study and six cohort studies were found which gave rates or risks of cancer specifically for veterinarians.

CASE-CONTROL STUDIES

It is rare for community based studies of cancer to report the risk for veterinarians separately as, in western countries, veterinarians account for only about $0.03 \%$ of the working population. As a result, most case-control studies combine the occupation of veterinarian with other professions or other health workers making it impossible to assess the risk of cancer specific to veterinarians. However, one case-control study of multiple myeloma based on occupation as recorded on death certificates did report the risk for veterinarians separately. ${ }^{84}$ The investigators found a risk of multiple myeloma in veterinarians compared with all other occupations of 3.2 (95\% CI 1.1 to 9.0 ) This was based on six cases of multiple myeloma in veterinarians out of nearly 12000 cases.

\section{COHORT STUDIES}

Description of studies

All published cohort studies of cancer in veterinarians have been mortality studies (table 3). Mortality is a reasonable measure of risk for those cancers with a high case fatality rate such as lung cancer. However, incidence is a better measure of risk for most cancers.

There have been two published studies which calculated proportional mortality ratios (PMRs) from deaths in registered veterinarians, both performed in the United States. ${ }^{85} 86$ One obtained the list of deceased veterinarians from all obituaries in a veterinary journal between the years 1947 and $1977 .^{86}$ The other used deaths notified to veterinary registration boards between the years 1960 and $1992 .{ }^{85}$ There have been four published cohort studies which presented standardised mortality ratios (SMRs) in registered veterinarians. ${ }^{87-90}$ All four cohort studies were performed during the 1950s and 1960s, one in Britain ${ }^{89}$ and the other three in the United States. The cohorts were formed from lists of registered veterinarians and were followed up to ascertain deaths. Both PMRs and SMRs have well known potential problems as measures of effect.

\section{Results from cohort studies}

Veterinarians do not seem to differ greatly from the general population for deaths from all cancers combined (table 3) The only significant finding was a PMR of 118 in one of the mortality studies. ${ }^{85}$ It would seem worth noting that veterinarians are usually considered to be a high socioeconomic group, and as such, may be expected to have a lower cancer mortality than the general population.

Veterinarians had about 30\% lower risk of lung cancer in all four studies which reported that risk..$^{85} 868889$ This is consistent with veterinarians' higher socioeconomic status and increased health knowledge, both of which would be associated with lower rates of smoking.

Both studies that reported PMRs noted significantly increased PMRs for colon cancer. ${ }^{8586}$ However, the one SMR study which presented results for colon cancer found the SMR to be only $103 .{ }^{89}$ It may be that the PMR for colon cancer is affected by the few deaths from lung cancer.

The larger PMR study found significantly increased PMRs for brain tumours based on 28 cases. ${ }^{86}$ Significantly increased risks of brain tumours were not reported in any other study.

Although increased death rates from melanoma were reported, these were based on few cases. An SMR of $727^{88}$ was based on three deaths and PMRs of $325^{85}$ and $161^{86}$ were based on seven and 24 deaths respectively. One of the risk factors for melanoma is exposure to sun, and it might be argued that veterinarians who have large animal practices spend considerable time outdoors. The SMR study found that two of the three veterinarians with melanoma were general practitioners, and the

Table 3 Cohort studies of cancer in veterinarians

\begin{tabular}{|c|c|c|c|}
\hline Cancer (ICD-9 code) & First author, year ${ }^{\text {ref }}$ & Cases (n) & Finding \\
\hline \multirow[t]{6}{*}{ All cancers combined } & Botts, $1966^{87}$ & 21 & SMR $=94$ \\
\hline & Schnurrenberger, $1977^{90}$ & 79 & $\mathrm{SMR}=112$ \\
\hline & Fasal, $1966^{88}$ & 29 & $\mathrm{SMR}=94$ \\
\hline & Kinlen, $1983^{89}$ & 228 & $\mathrm{SMR}=84$ \\
\hline & Blair, $1982^{86}$ & 832 & $\mathrm{PMR}=101$ \\
\hline & Miller, $1995^{85}$ & 116 & $\mathrm{PMR}=118(95 \%$ CI 101 to 138$)$ \\
\hline \multirow[t]{3}{*}{ Stomach (151) } & Kinlen, $1983^{89}$ & 26 & SMR $=69$ \\
\hline & Blair, $1982^{86}$ & 47 & PMR $=65(\mathrm{p}<0.005)$ \\
\hline & Miller, $1995^{85}$ & 5 & $\mathrm{PMR}=119(95 \%$ CI 50 to 283$)$ \\
\hline \multirow[t]{3}{*}{ Colon (153) } & Kinlen, $1983^{89}$ & 21 & SMR $=103$ \\
\hline & Blair, $1982^{86}$ & 111 & $\mathrm{PMR}=134(\mathrm{p}<0.005)$ \\
\hline & Miller, $1995^{85}$ & 14 & $\mathrm{PMR}=169(95 \%$ CI 101 to 282$)$ \\
\hline \multirow[t]{4}{*}{ Lung $(162,163)$} & Fasal, $1966^{88}$ & 5 & SMR $=68$ \\
\hline & Kinlen, $1983^{89}$ & 61 & $\mathrm{SMR}=65$ \\
\hline & Blair, $1982^{86}$ & 115 & PMR $=62(\mathrm{p}<0.005)$ \\
\hline & Miller, $1995^{85}$ & 22 & $\mathrm{PMR}=69(95 \%$ CI 47 to 103$)$ \\
\hline \multirow[t]{2}{*}{ Melanoma (190) } & Fasal, $1966^{88}$ & 3 & $\mathrm{SMR}=727$ \\
\hline & Miller, $1995^{85}$ & 7 & $\mathrm{PMR}=325(95 \%$ CI 162 to 652$)$ \\
\hline \multirow[t]{2}{*}{ Skin cancer (190-191) } & Kinlen, $1983^{89}$ & 2 & $\mathrm{SMR}=81$ \\
\hline & Blair, $1982^{86}$ & 24 & $\mathrm{PMR}=161(\mathrm{p}<0.025)$ \\
\hline \multirow{2}{*}{ Central nervous system (193) } & Blair, $1982^{86}$ & 28 & PMR $=163(p<0.01)$ \\
\hline & Miller, $1995^{85}$ & 3 & $\mathrm{PMR}=95(95 \% \mathrm{CI} 31$ to 294$)$ \\
\hline \multirow[t]{2}{*}{ All lymphoheamatopoietic (200-205) } & Blair, $1982^{86}$ & 112 & $\mathrm{PMR}=149(\mathrm{p}<0.005)$ \\
\hline & Miller, $1995^{85}$ & 12 & $\mathrm{PMR}=119(95 \% \mathrm{CI} 68$ to 208$)$ \\
\hline \multirow[t]{2}{*}{ Lymphoma (200-202) } & Fasal, $1966^{88}$ & 2 & $\mathrm{SMR}=103$ \\
\hline & Kinlen, $1983^{89}$ & 11 & $S M R=83$ \\
\hline
\end{tabular}


third was a large animal practitioner. ${ }^{88}$ Miller and Beaumont found that self employed and employee veterinarians had significantly increased PMRs from melanoma whereas government and educator veterinarians did not. ${ }^{85}$ Blair and Hayes found the risk to be higher in non-small animal veterinarians. ${ }^{86}$ Melanoma is also known to be more common in higher socioeconomic groups, which may be an alternative explanation of the findings, although it would not explain the higher rates in large animal veterinarians compared with small animal veterinarians.

Lymphohaemopoietic cancers are of interest in this group because of the finding that agricultural workers in general have increased risks of lymphohaematopoietic cancers. The largest study of veterinarians found a significantly increased PMR of 149 for all lymphohaematopoietic cancers combined. ${ }^{86}$ Of the lymphohaematopoietic cancer types in this study, there were significantly increased PMRs for Hodgkin's disease (PMR=187, $\mathrm{n}=18$ ) and "other lymphatic tissue" (ICD-7 202, 203, $205, \mathrm{PMR}=192, \mathrm{n}=26)$. Smaller studies have tended not to find a significantly increased risk.

The increases in both melanoma and lymphohaematopoietic cancers are interesting in the light of recent discussion of a possible link between sun exposure, skin cancer, and non-Hodgkin's lymphoma. This theory is based on findings that skin cancer and non-Hodgkin's lymphoma are found in association more often than expected ${ }^{91}{ }^{92}$ and some studies show that sun exposure and nonHodgkin's lymphoma are related. ${ }^{93}$ Th This theory is still speculative but, if more evidence accumulates in its favour, it would make it less likely that the possible increases in risk of nonHodgkin's lymphoma in veterinarians are associated with pesticides or zoonoses.

\section{Conclusions}

The few studies available which have considered the issue of cancer in veterinarians report a mortality from all cancers about the same as in the general population. The mortalities from lung cancer are significantly decreased, whereas there is some suggestion of increased mortality from lymphohaematopoietic cancers, melanoma, and possibly colon cancer. None of these studies have been able to assess the role of specific exposures in cancer risk, and all have used mortality rather than incidence.

Veterinarians have significant exposure to several known and potential carcinogens, particularly radiation, anaesthetics, insecticides, and animal viruses.

There are known risks of skin cancer, thyroid cancer, and leukaemia with exposure to $x$ rays, but the doses received in veterinary practice are probably insufficient to cause major increases in risk, unless there are problems with the equipment or with radiology procedures. The carcinogenic risk from anaesthetics is probably negligible in this occupation. Insecticides for parasite control in large and small animal practices are potentially associated with lymphohaematopoietic cancers. The evidence for car- cinogenic zoonotic organisms causing cancer in humans, although intriguing, is still speculative.

Studies of veterinarians that use better exposure assessment and examine incidence rather than mortality from cancer may shed light on risks not only for veterinarians but for a range of other occupations related to medicine and animals - such as animal handlers, veterinary nurses, dentists, radiographers, anaesthetists, and some farmers.

1 Steele L, Wilkins JR. Occupational exposures and risks of spontaneous abortion among female veterinarians. Int $\mathcal{F}$ Occup Environ Health 1996;2:26-36.

2 Wiggins P, Schenker MB, Green R, et al. Prevalence of hazardous exposures in veterinary practice. Am $\mathcal{F}$ Ind $M e d$ 1989;16:55-66.

3 Moritz S, Hueston W, Wilkins J. Patterns of ionizing radiation exposure among women veterinarians. $\mathcal{f} \mathrm{Am}$ Vet $\mathrm{Med}$ Assoc 1989;195:737-9.

4 McCaffery A. Radiological protection in veterinary practice. Memorandum. Chilton, UK: National Radiological ProtecMemorandum. Chilton, UK: National Radiological Protec-
tion Board Memorandum, 1993. (Report No NRPBtion Bo

5 Wheelton R. A study of the arrangements for radiological protection in twenty-three veterinary practices in Scotland. Memorandum. Chilton, UK: National Radiological Protection Board, 1977. (Report No NRPB-R66.)

6 Jacobson G, Van Farowe DE. Survey of $x$ ray protection practices among Michigan veterinarians. f Am Vet Med Assoc 1964;145:793-7.

7 Dixon R. Exposure doses of X-radiation incurred during veterinary diagnostic radiological examinations. Aust Vet $\mathcal{F}$ 1986;44:299-303.

8 Moritz S, Wilkins JR, Hueston WD. Evaluation of radiation safety in 29 Central Ohio veterinary practices. Am $\mathcal{F}$ Public Health 1989;79:895-6.

9 Grazer R, Meislin H, Westerman B, et al. A nine year evaluation of emergency department personnel exposure to ionizing radiation. Ann Emerg Med 1987;16:340-2.

10 Banu $\mathrm{H}$, Alam $\mathrm{M}$, Chowdhury $\mathrm{M}$, et al. Assessment of occupational and patient dose from diagnostic and therapeutic radiation exposure using thermoluminescent dosimetry. Health Phys 1998;74:478-80.

11 Vehmas T. Radiation exposure during standard and complex interventional procedures. Br $\mathcal{F}$ Radiol 1997;70: 296-8.

12 Goldstone K, Wright I, Cohen B. Radiation exposure to the hands of orthopaedic surgeons during procedures under fluoroscopic $x$ ray control. Br f Radiol 1993;66:899-901.

13 Samet J. Epidemiologic studies of ionizing radiation and cancer: past successes and future challenges. Environ Health Perspect 1997;105(suppl 4):883-9.

14 Matanoski G, Seltser R, Sartwell PE, et al. The current mortality rates of radiologists and other physician specialists: specific causes of death. Am f Epidemiol 1975;101:199210 .

15 Smith P, Doll R. Mortality from cancer and all causes among British radiologists. Br F Radiol 1981;54:187-94.

16 Carpenter L, Swerdlow AJ, Fear NT. Mortality of doctors in different specialties: findings from a cohort of 20000 NHS different specialties: findings from a cohort of 20 000 NHS

17 Wingren G, Hallquist, A, Hardell, L. Diagnostic $x$ ray exposure and female papillary thyroid cancer: a pooled analysis of two Swedish studies. Eur F Cancer Prev 1997;6:550-6.

18 Eklund G, Izikowitz L, Molin C. Malignant tumours in Swedish dental personnel: a comparative study with the total population as well as with some specific occupational groups. Swed Dent f 1990;14:249-54

19 Rix B, Lynge E. Cancer incidence in Danish healthcare workers. Scand F Soc Med 1996;24:114-20.

20 Vagero D, Swerdlow AJ, Beral V. Occupation and malignant melanoma: a study based on cancer registration data in England and Wales, and in Sweden. Br f Ind Med 1990;47:

21 Ruby D, Buchan RM, Gunter BJ. Waste anaesthetic gas and vapor exposures in veterinary hospitals and clinics. Am Ind Hyg Assoc f 1980;41:229-31.

22 Milligan J, Sablan JL. A survey of waste anesthetic gas concentrations in US Air Force veterinary surgeries. $\mathcal{F} \mathrm{Am}$ Vet Med Assoc 1980;177:1021-2.

23 Gardner R, Hampton J, Causton J. Inhalation anaesthetics: exposure and control during veterinary surgery. Ann Occup Hyg 1991;4:377-88.

24 Ward G, Byland, RR. Concentration of halothane in veterinary operating and treatment rooms. F Am Vet Med Assoc 1982;180:174-7.

25 Wingfield W, Ruby DL, Buchan RM, et al. Waste anesthetic gas exposures to veterinarians and animal technicians. $\mathcal{f}$ Am Vet Med Assoc 1981;178:399-402.

26 Korczynski R. Anesthetic gas exposure in veterinary clinics. Appl Occup Environ Hygiene 1999;14:384-90.

27 Burkhart J, Stobbe T. Real-time measurement and control of waste anesthetic gases during veterinary surgery. Am Ind Hyg Assoc 1990;51:640-5. 
28 Milligan J, Sablan JL, Short CE. Waste anesthetic gas concentrations in a veterinary recovery room. $7 \mathrm{Am}$ Vet Med Assoc 1982;181:1540-1.

29 Dreesen D, Jones GL, Brown J, et al. Monitoring for trace anesthetic gases in a veterinary teaching hospital. $7 \mathrm{Am}$ Vet Med Assoc 1981;179:797-9.

30 Guirguis S, Pelmear P, Roy M, et al. Health effects associated with exposure to anaesthetic gases in Ontario hospital personnel. Br f Ind Med 1990;47:490-7.

31 International Agency for Research on Cancer. Anaesthetics. Lyon, France: IARC, 1987.

32 Neil H, Fairer JG, Coleman MP, et al. Mortality among male anaesthetists in the United Kingdom, 1957-83. BMף 1987;295:360-2.

33 Spence A, Cohen E, Brown B, et al. Occupational hazards for operating room-based physicians. $\mathcal{F} A M A$ 1997;238: 955-9.

34 Cohen E, Brown BW, Wu ML, et al. Occupational disease in dentistry and chronic exposure to trace anesthetic gases. $f$ Am Dent Assoc 1980;101:21-31.

35 Beat V, Morgan DP. Evaluation of hazards involved in treating cattle with pour-on organophosphate insecticides. $\mathcal{F} \mathrm{Am}$ ing cattle with pour-on organoph.

36 Ames R, Brown S, Rosenberg J, et al. Health symptoms and occupational exposure to flea control products among California pet handlers. Am Ind Hyg Assoc 1989;50:46672.

37 Bukowski J, Brown C, Korn LR, et al. Prevalence of and potential risk factors for symptoms associated with insecticide use among animal groomers. F Occup Environ Health 1996;38:528-34.

38 Davis J, Brownson R, Garcia R, et al. Family pesticide use and childhood brain cancer. Arch Environ Comtam Toxicol 1993;24:87-92.

39 Pogoda J, Preston-Martin S. Household pesticides and risk of pediatric brain tumors. Environ Health Perspect 1997;105: $1214-20$

40 Glickman L, Schofer F, McKee L, et al. Epidemiologic study of insecticide exposures, obesity, and risk of bladder cancer in household dogs. F Toxicol Environ Health 1989;28:40714.

41 Pearce N, Reif JS. Epidemiologic studies of cancer in agricultural workers. Am f Ind Med 1990;18:133-48.

42 Blair A, Hoar Zahm S, Pearce NE, et al. Clues to cancer etiology from studies of farmers. Scand $\mathcal{F}$ Work Environ Health 1992;18:209-15.

43 Cantor K, Blair A, Everet G, et al. Pesticides and other agricultural risk factors for non-Hodgkin's lymphoma among
men in Iowa and Minnesota. Cancer Res 1992;52:2447-55.

44 Tatham L, Tolbert P, Kjeldsberg C. Occupational risk factors for subgroups of non-Hodgkin's lymphoma. Epidemiology 1997;8:551-8

45 Zahm S, Weisenburger D, Saal R, et al. The role of agricultural pesticide use in the development of non-Hodgkin's lymphoma in women. Arch Environ Health 1993;48:353-8.

46 Blair A, Cantor K, Hoar-Zahm S. Non-Hodgkin's lymphoma and agricultural use of the insecticide lindane. Am f Ind Med 1998;33:82-7.

47 Blair A, Thomas TL. Leukemia among Nebraska farmers: a death certificate study. Am ₹ Epidemiol 1979;110:264-73.

48 Cantor K, Blair A. Farming and mortality from multiple myeloma: a case-control study with the use of death certificates. F Natl Cancer Inst 1984;72:251-5.

49 Saftlas A, Blair A, Cantor KP, et al. Cancer and other causes of death among Wisconsin farmers. Am f Ind Med 1987;11:119-29.

50 Schneider R, Riggs JL. A serologic survey of veterinarians for antibody to feline leukaemia virus. $\mathcal{F} \mathrm{Am}$ Vet Med Assoc 1973;162:217-19.

51 Johnson E, Griswold CM. Oncogenic retroviruses of cattle, chickens and turkeys: potential infectivity and oncogenicity for humans. Med Hypotheses 1996;46:354-6.

52 Minson A, Neil J, McCrae M, ed. Viruses and cancer. Cambridge: Cambridge University Press, 1994.

53 Johnson E, Fischman HR, Matanoski GM, et al. Occurrence of cancer in women in the meat industry. Br f Ind Med of cancer in wom

54 Guberan E, Usel M, Raymond L, et al. Mortality and incidence of cancer among a cohort of self employed butchers from Geneva and their wives. Br F Ind Med 1993, 50:1008-16.

55 Coggan D, Pannett B, Pippard E, et al. Lung cancer in the meat industry. $\mathrm{Br}$ f Ind Med 1989;46:188-91.

56 Johnson E, Shorter C, Rider B, et al. Mortality from cancer and other diseases in poultry slaughtering/processing plants. Int f Epidemiol 1997;26:1 142-50.

57 Metayer C, Johnson ES, Rice JC. Nested case-control study of tumors of the hemopoietic and lymphatic systems
among workers in the meat industry. Am F Epidemiol 1998; among work

58 Franceschi S, Serraino D, La Vecchia C, et al. Occupation and risk of Hodgkin's disease in north-east Italy. Int $\mathscr{f} \mathrm{Can}-$ cer 1991;48:831-5.

59 Pearce N, Sheppard RA, Smith AH, et al. Non-Hodgkin's lymphoma and farming: an expanded case-control study. Int $\mathcal{F}$ Cancer 1987;39:155-61.

60 Loomis D, Savitz DA. Occupation and leukemia mortality among men in 16 States: 1985-7. Am f Ind Med 1991;19: 509-21.

61 Morton W, Marjanovic D. Leukemia incidence by occupation in the Portland-Vancouver metropolitan area. Am f Ind Med 1984;6:185-205.
62 Johnson E, Dalmas D, Noss J, et al. Cancer mortality among workers in abattoirs and meatpacking plants: an update. Am f Ind Med 1995;27:389-403.

63 Johnson E. Nested case-control study of lung cancer in the meat industry. F Natl Cancer Inst 1991;83:1337-9.

64 Alavanja M, Brownson R, Berger E, et al. Avian exposure and risk of lung cancer in women in Missouri: population based case-control study. BMF 1996;313:1233-5.

65 Gardiner A, Forey BA, Lee PN. Avian exposure and bronchogenic carcinoma. BMf 1992;305:989-92.

66 Kohlmeier L, Arminger G, Bartolomeycik S, et al. Pet birds as an independent risk factor for lung cancer: case-control study. BMF 1992;305:986-9.

67 Morabia A, Stellman S, Lumey LH, et al. Parakeets, canaries, finches, parrots, and lung cancer: no association. $\mathrm{Br} \mathcal{F}$ Cancer 1998;77:501-4

68 Modigh C, Axelsson G, Alavanja M, et al. Pet birds and risk of lung cancer in Sweden: a case-control study. BMF 1996; 313:1236-8

69 Britton J, Lewis S. Pet birds and lung cancer: now no evidence of a link. BMF 1996;313:1218-19.

70 Gardner M. Current information on feline and canine cancers and relationship of lack of relationship to human cancer. F Natl Cancer Inst 1971;46:281-90.

1 Schneider R. The natural history of malignant lymphoma and sarcoma in cats and their associations with cancer in man and dog. F Am Vet Med Assoc 1970;157:1753-8.

72 Schneider R. Human cancer in households containing cats with malignant lymphoma. Int F Cancer 1972;10:338-44.

73 Bross I, Bertell R, Gibson R. Pets and adult leukaemia. Am 7 Public Health 1972;62:1520-31.

74 Donham K, VanDer Maaten MJ, Miller JM, et al. Seroepidemiologic studies on the possible relationships of human and bovine leukemia. $\mathcal{F}$ Natl Cancer Inst 1977;59: human

75 Donham K, Berg JW, Sawin RS. Epidemiologic relationships of the bovine population and human leukemia in Iowa. Am $\mathcal{F}$ Epidemiol 1980;112:80-92.

76 Donham K, Burmeister LF, VanLier SF, et al. Relationships of bovine leukemia virus prevalence in dairy herds and density of dairy cattle to human lymphocytic leukemia. $\mathrm{Am}$ F Vet Res 1987;48:235-8.

77 Kranz J. Defining and measuring exposure in epidemiologic studies of potential zoonoses. F Am Vet Med Assoc 1983;183:1454-8.

78 Johnson E. Poultry oncogenic retroviruses and humans. Cancer Detect Prev 1994;18:9-30.

79 Johnson E, Nicholson LG, Durack DT. Detection of antibodies to avian leukosis/sarcoma viruses (ALSV) and reticuloendotheliosis viruses (REV) in humans by ELISA. Cancer Detect Prev 1995;19:394-404.

80 Johnson E, Overby L, Philpot R. Detection of antibodies to avian leukosis/sarcoma viruses and reticuloendotheliosis viruses in humans by western blot assay. Cancer Detect Prev 1995; 19:472-86.

81 Choudat D, Dambrine G, Delemotte B, et al. Occupational exposure to poultry and prevalence of antibodies against Marek's disease virus and avian leukosis retroviruses. Occup Environ Med 1996;53:403-10.

82 Krakower J, Aaronson SA. Seroepidemiologic assessment of feline leukaemia virus infection risk for man. Nature 1978; 273:463-4.

83 Hardy W, Hess PW, MacEwen EG, et al. Biology of feline leukemia virus in the natural environment. Cancer Res 1976;36:582-8

84 Figgs L, Dosemeci M, Blair A. Risk of multiple myeloma by occupation and industry among men and women: a 24-state death certificate study. F Occup Med 1994;36: $1210-21$.

85 Miller J, Beaumont JJ. Suicide, cancer, and other causes of death among California veterinarians, 1960-92. Am f Ind Med 1995;27:37-49.

86 Blair A, Hayes HM. Mortality patterns among US veterinarians 1947-77: an expanded study. Int $\mathcal{F}$ Epidemiol 1982;11:391-7

87 Botts R, Edlavitch S, Payne G. Mortality of Missouri veterinarians. F Am Vet Med Assoc 1966;149:499-504.

88 Fasal E, Jackson EW, Klauber MR. Mortality in California veterinarians. Fournal of Chronic Diseases 1966;19:293-306.

89 Kinen $L$ Mortality among British veterinary surgeons. $B M \mathcal{F} 1983 ; 287: 1017-19$

90 Schnurrenberger P, Martin RJ, Walker JF. Mortality in Illinois veterinarians. F Am Vet Med Assoc 1977;110:1071-5.

91 Hall P, Rosendahl I, Mattsson A, et al. Non-Hodgkin's lymphoma and skin malignancies: shared etiology? Int $\mathcal{f}$ Cancer 1995;62:519-22.

92 Wassberg C, Thorn M, Yuen J, et al. Cancer risk in patients with earlier diagnosis of cutaneous melanoma in situ. Int $\mathcal{F}$ Cancer 1999:83:314-17.

93 Adami J, Frisch M, Yuen J, et al. Evidence of an assocation between non-Hodgkin's lymphoma and skin cancer. BMF 1995;310:1491-5.

94 Bentham G. Association between incidence of nonHodgkin's lymphoma and solar ultraviolet radiation in England and Wales. BMF 1996;312:1128-31.

95 Noah D, Kramer CM, Verbsky MP, et al. Survey of veterinary professionals and other veterinary conference attendees for antibodies to Bartonella henselae and B quintane. $\mathcal{F}$ Am Vet Med Assoc 1997;210:342-4.

96 Nowotny N, Deutz A, Fuchs K, et al. Prevalence of swine influenza and other viral, bacterial, and parasitic zonoses in influenza and other viral, bacterial, and paras

97 Robinson R, Metcalfe RV. Zoonotic infections in veterinarians. New Zealand Veterinary fournal 1976;24:201-11. 
98 Schnurrenberger P, Helwig JH, Bashe WJ. The incidence of zoonotic infections in veterinary students. $7 \mathrm{Am}$ Vet Med zoonotic infections in
Assoc 1964;144:384-6.

Assoc 1964;144:384-6.
99 Morse E, Allen V, Worley G. Brucellosis and leptospirosis serological test results on serums of Wisconsin veterinarians. F Am Vet Med Assoc 1955;126:59.

100 Thibon M, Villiers V, Souque P, et al. High incidence of Coxiella burnetii markers in a rural population in France. Eur F Epidemiol 1996;12:509-13.

101 Htwe K, Yoshida T, Hayashi S, et al. Prevalence of antibodies to Coxiella burnetii in Japan. $f$ Clin Microbiol 1993;31:722-3.

102 Marrie T, Fraser J. Prevalence of antibodies to Coxiella burnetii among veterinarians and slaughterhouse workers in Nova Scotia. Can Vet f 1985;26:181-4.
103 Schnurrenberger P, Hanson LE, Martin RJ. Infections with Erysipelothrix, Leptospira, and Chlamydia in Illinois veterinarians. International fournal of Zoonoses 1978;5:55-61.

104 Milham S. Leukemia and multiple myeloma in farmers. Am f Epidemiol 1971;94:307-10.

105 Pearce N, Sheppard R, Howard J, et al. Leukemia among New Zealand agricultural workers: a cancer registry-based study. Am f Epidemiol 1986;124:402-9.

106 Pearce N, Smith A, Howard J, et al. Case-control study of multiple myeloma and farming. Br f Cancer 1986;54:493500 .

107 Clavel J, Mandereau L, Cordier S, et al. Hairy cell leukaemia, occupation, and smoking. Br f Haematol 1995;91: $154-61$. 